\title{
O Brasil colonial na literatura contemporânea
}

\author{
Maria do Carmo Lanna Figueiredo \\ PUC Minas
}

Para Julieta de Godoy Ladeira, in memoriam.

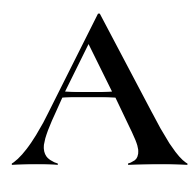

comunicação O Brasil colonial na literatura contemporânea traz uma pequena amostra de um projeto interdisciplinar que venho desenvolvendo no Programa de Pósgraduação em Letras da PUC Minas, área de Literaturas de Língua Portuguesa, com a participação de doutorandos, mestrandos e bolsistas de Iniciação Cientifica. Financiado pelo Fundo de Incentivo à Pesquisa FIP, da PUC Minas, o corpus do projeto abrange obras de escritores brasileiros da atualidade, com vistas à caracterização do literário em sua relação com o extra-ficcional, a partir de várias configurações do escritor enquanto leitor do sistema literário e histórico-cultural do país. Faz parte da pesquisa a análise de Sinais de vida no planeta Minas, de Fernando Gabeira (1982), que focalizei a partir do processo narrativo que se constrói no diálogo entre a ficção e a reportagem, e entre a literatura e a sociedade. Considerei, no livro, o entrelaçar do episódio Ângela Diniz, "a pantera de Minas", que ocupou a curta duração das manchetes dos jornais das décadas de 60 e 70, com a vida de outras mineiras famosas e míticas - Chica da Silva de Diamantina, Beja do Araxá, Olímpia de Ouro Preto e Tiburtina de Montes Claros. O enfoque propiciou-me o estudo de questões referentes aos gêneros literários e ao espaço social da mulher. Além disso, pude detectar, no citado romance, uma linha da produção contemporânea que se atualiza e que procuro destacar na presente comunicação: a forte presença do Brasil colonial nas obras atuais. 
Na vertente, lembro outro volume, também incluído no corpus do projeto, Boca de chafariz, de Rui Mourão, publicado em 1991 pela Villa Rica Editora. No romance, faz-se perceptível a tensão entre passado e atualidade, assinalada na articulação de imagens que o compõem e que se referem ora ao povoado que irá se transformar na Vila Rica colonial, ora à cidade atual de Ouro Preto, reconhecida como Patrimônio Cultural da Humanidade. Tais imagens, intercaladas e superpostas pelo jogo ficcional, ampliam e questionam o espaço que a memória coletiva construiu para a cidade. Com efeito, Ouro Preto vem-se mantendo, enquanto sustentáculo de diversas representações sígnicas que tendem a imobilizá-la no espaço mítico da construção da identidade, tanto a regional dos mineiros, quanto a do país. Por este motivo, a força do passado e da tradição identitária de cena acaba por dificultar o convívio da cidade com o mundo contemporâneo, trazendo problemas a sua população e a seus governantes.

O romance, construindo-se na confluência entre o ficcional e o histórico, intervém nessas representações sígnicas já canonizadas pela tradição, ao incentivar o diálogo sem hierarquias entre o passado e o presente. Graças a esse subterfúgio narrativo, explicita a tensão vivenciada pela cidade e seus habitantes, em busca do difícil equilíbrio entre as forças do passado - a necessidade de preservar a identidade da cultura colonial, Vila Rica e seus monumentos, enquanto ela ainda existe -, e as demandas do presente - a necessidade de situar-se no mundo atual, participando do desenvolvimento econômico e industrial de Ouro Preto. Esse intercâmbio permite ainda que se visualize um amplo painel da cidade.

Pode-se incluir A rainha dos cárceres do Grécia, romance de Osman Lins, publicado pela Melhoramentos em 1976, no rol das produções literárias contemporâneas que se debruçam sobre o Brasil colônia. Destacando, no caso, o episódio da invasão holandesa e interpenetrando-o ao momento ditatorial da década de 70, o livro reflete sobre os "cárceres" que aprisionam o povo e o escritor brasileiros. Lembre-se que a busca de identidade nacional, na tradição literária brasileira responde à necessidade de se caracterizar a 
produção da colônia, conferindo-lhe estatuto de legitimidade. O sentimento nacional vem, pois, acompanhado do desejo, ou mesmo da necessidade de se criar a imagem de uma nação coesa, unida nacionalmente, o que acaba por orientar as representações do país no campo literário.

Nesse sentido, focalizo o romance como participante ativo da construção da memória coletiva e da tradição do país. O discurso ficcional, desvinculado da preocupação de veracidade e objetividade, alcança intervir tanto no preenchimento de lacunas deixadas pelo discurso histórico, quanto no questionamento de verdades históricas estabelecidas, ampliando, por esse viés, o significado de fatos e figuras do passado, ao mesmo tempo que contribui para a sua divulgação e conservação. Ao trazer à tona um aspecto bastante significativo do tema proposto, quando articula ficção, tradições populares do nordeste e obras da historiografia sobre as guerras holandesas, o romance de Osman Lins supera com eficácia as fronteiras que separam fictício, imaginário e realidade e permite que se caracterize o referencial a que remete, sem se deixar determinar por ele. ${ }^{1}$

A rainha dos cárceres do Grécia vale-se, para descrever as cenas das lutas que se travaram entre luso-brasileiros e holandeses, de citações dos compêndios de história. Aparecendo entre aspas, acopladas ao discurso romanesco que faz indicação das suas fontes ao pé de página, tal estratégia será assim comentada pelo narrador do romance:

Toda iconografia guerreira superposta ao cenário do romance, ponto por ponto, recompõe, com poucas mudanças na seqüência e nos fatos abonados pelos historiadores, a conquista, em 1630, de Olinda e de Recife pelos homens de Lonck e Waerdeburch. (...) Observaremos o paralelismo entre as cenas de guerra que ensombram o romance e a entrado das forças holandesas em Pernambuco: e seguireis a romancista no seu trabalho de encobrir a natureza dessas alusões, numa espécie de conflito entre História e Poesia. ${ }^{2}$

${ }^{1}$ Cf. ISER, 1996. p. 17-37.

${ }^{2}$ LINS, 1976. p. 127-8. 
O conflito entre História e Poesia manifesta-se, no texto citado, mediante o uso explícito da intertextualidade com o discurso histórico e mediante o desejo do autor de incluir-se nas versões existentes sobre o tema, a partir da ótica dos excluídos. Dessa forma, tornase possível abranger uma ampla faixa de conteúdos ideológicos que envolvem a presença holandesa no Brasil, interpretados por uma sucessão interminável de significados a ela atribuídos pelas diversas personagens que povoam o romance. Como as guerras holandesas ainda não receberam um tratamento histórico definitivo, o liame que une ficção e realidade esgarça-se na profusão de detalhes que contribuem na sua criação. Por outro lado, o tratamento literário que é dado ao episódio histórico pode ser relacionado com um projeto de construção da identidade sob o prisma pelo qual o escritor vê os outros, a si mesmo, o mundo e a mediação pela qual ele se comunica com a sociedade. O fato de Osman Lins ser pernambucano de ascendência holandesa não deve ser considerado, no caso, mera coincidência. Valorizar, no entanto, a equivalência da história e da literatura, na interpretação dos fatos da realidade brasileira que se deixam ler no romance, possibilita enxergar uma feição que impede a obra de perder-se nas contradições de ordem puramente individual.

Evaldo Cabral de Mello, em Rubro veio, o imaginário do restauração pernambucana, chama a atenção para o fato de o sentimento nativista pernambucano, mais violentamente antilusitano do que em outras partes do Brasil, ter elaborado, a partir da segunda metade do século XVII e até os finais do século XIX, um tipo de experiência da ocupação holandesa diferenciado, no que diz respeito à história e à memória coletiva. Ao explorar as deformações que o nativismo impôs à visão local da experiência holandesa, o autor afirma que as guerras contra Holanda ocuparam um lugar central na ideologia nativista do nordeste. Herdeiro das crônicas lusobrasileiras, este imaginário tendeu a ler a história do período como as gestas de determinados grupos ou camadas sociais, enquanto que a imaginação popular inclinou-se a representar o período holandês com as cores do maravilhoso e até do sobrenatural. Atribuíam-se aos holandeses obras de engenharia que atraíam a imaginação local, 
mesmo quando eram portuguesas. E é notável a difusão das lendas relativas a tesouros enterrados, os casos de ruídos e de rumores bélicos no silêncio das noites de Olinda, as luzinhas misteriosas avistadas pelos de Recife, as almas de soldados tombados, assim como a lenda da donzela da mangueira. ${ }^{3}$

A meu ver, as considerações do historiador falam de inúmeras possibilidades de aproveitamento literário desse imaginário e chega mesmo a surpreender o fato de existirem relativamente poucas obras sobre o assunto. O encontro da literatura com a história no romance vai, pois, permitir que a urgência da participação, a necessidade de explicar a realidade social e de opinar sobre ela invada o espaço literário.

A temática da invasão será um dos eixos mais centrais do livro de Osman Lins, "romance de permutação, onde tudo invade tudo". A história constrói-se como um ensaio e estrutura-se como o diário de um professor de Ciências Naturais de São Paulo que viveu com a romancista pernambucana Julia Marquezim Enone, autora do livro inédito $A$ rainha dos cárceres do Grécia. Pode-se questionar a existência do romance de Júlia que só se conhece pelos breves extratos, longos comentários e alusões que a ele faz o professor, em seu diário. O leitor do diário depara-se, pois, com um professor que não existe e é personagem do romance de Osman Lins. Referência indireta à censura que aprisiona as obras de contestação na trilha da divulgação clandestina e seus autores nos "cárceres" da ditadura, marcada pela clandestinidade que a impede de circular livremente, a obra em edição policopiada de Julia se integra à obra publicada do escritor Osman Lins que também se chama $A$ rainha dos cárceres da Grécia. Será este um dos motivos que explicariam as inúmeras entradas no mundo referencial brasileiro pela via de uma obra que se coloca como um texto ficcional e que, graças ao diário, gênero tão ligado à memória, rastreia sentidos que se perderam nas inexatidões da memória coletiva e se encontram esparsos em fragmentos de diferentes textos e no contexto presente e passado da história do Recife?

${ }^{3}$ Cf .MELLO, 1986. p. 28. 
A partir da contestação de um traço da sociedade colonial - o apagamento da memória dos holandeses programada pela elite lusobrasileira hegemônica -, A rainha dos cárceres do Grécia torna-se cúmplice das formas culturais deixadas à margem pela cultura letrada do dominador, se bem que conservadas pela cultura popular. Partícipe da memória coletiva, subversivo, clandestino, fragmentado, o romance tece um pacto explícito com os silenciados, impondo-se a tarefa de reconstrução, pelo imaginário, da possibilidade de homens e pais livres. Criando o presente, recriando o passado, mapeando o dia-a-dia do povo oprimido, tenta reconstruir/recontar o corpo fragmentado de uma Olinda, de um Recife, de um São Paulo, enfim, de um Brasil subjugado por vários tipos de opressão, metaforizados pelos cárceres da Grécia.

Compõem o romance trechos de jornais da década de 70 , combinações de textos literários e históricos de várias épocas, retalhos de lembranças das personagens: uma jovem empregada doméstica - Maria de França; uma escritora - Julia Marquezim Enone; um professor - o ensaísta e narrador. Esses fragmentos acolhem a tensão entre lembrar e esquecer, verdade e invenção, aventada por outra personagem, a gata Memosina que, esquecendose da própria natureza, se confunde com rato, galinha, lontra. Metonímia da ficção de que participa, o animal concretiza o jogo do esquecimento e da lembrança refletido nela, jogo que permite o ir e vir do romance aos gêneros ensaio e diário, assim como permite à obra ligar-se à realidade histórica e ficcional, ao presente e ao passado. No livro, confrontam-se o esquecimento e as desfigurações da memória com o desejo de conservar, pela literatura, aquilo que dela persiste em fragmentos e dispersão.

O romance, tendo sido escrito numa das fases mais fortes da censura imposta pelo regime militar, repudia a política ditatorial e o cerceamento de liberdades civis e de escrita em que se insere, recusa o cerceamento dessas liberdades e faz dessa recusa uma de suas bases de sustentação. O problema da relação indivíduo e liberdade ocupa amplo espaço em $A$ rainha dos cárceres da Grécia, enunciado no título e veiculado pela estrutura e enredo, em que a ausência de liberdade mina todo o tecido social e narrativo, como é o caso do 
tratamento que o romance confere à presença holandesa no Brasil.

O livro exclui de sua temática o triunfo e opta pela "gesta sem fulgor" dos grupos de desvalidos e marginalizados sociais, focalizando as cenas da ocupação do Recife pelos holandeses e suas conseqüências para o povo. O narrador considera que os quadros, evocando a vitória do país e a expulsão dos holandeses, como os do livro $O$ Valeroso Lucideno de Frei Manuel Calado que celebra a libertação de Olinda, não teriam cabimento no romance de Julia, por serem apenas uma expressão daquela retórica sem consistência que povoa os relatos oficiais E assim justifica a opção da escritora:

Juba Marquezim Enone traz para o Recife, condenando-os a uma vida sem glória e inteiramente anônima, heróis (quem sabe até que ponto reais) da História do Brasil. (p. 168)

Julia M. Enone, com todas as suas leituras, era, sem forçar e sem ostentar, uma mulher do povo e com a aptidão para falar no seu nome, para ver do seu lado. (...) Inversamente, os ídolos nacionais, no Brasil, os consagrados com monumentos e nomes nas vias públicas, se realizaram feitos memoráveis, sempre guardaram distância do povo e indiferença pelos humilhados. Imersos em sonhos aristocráticos, moviam-nos ideais abstratos; ou de poder; ou nenhum. Os mecanismos oficiais, reconhecendo-os por motivos diversos, servidores seus, é que os levariam ao que chama Talleyrand, a 'canonização laica'. Julia Marquezim Enone derrubaos dos pedestais, priva-os de títulos, dos bens e dos vestes - se militares dos dragonas e das armas -, troca ou adultera os seus nomes e atira-os no limbo do serviço público, mais ou menos como Dante mete inimigos seus no Inferno. (p. 174)

Com efeito, se no enredo de $A$ rainha dos cárceres da Grécia mostram-se as façanhas da Colônia, estas apresentam-se como o que delas restou na memória coletiva, mediadas pela "iconografia" guerreira, pelos temas de escolas de samba e pelos eventos folclóricos. Tornam-se, assim, incompreensíveis aos olhos de Maria de França, que é incapaz de interpretá-las ou distingui-las do seu dia-a-dia conturbado pela loucura e pobreza. E mediante tal estratégia narrativa que Maria de França, personagem pobre, empregada doméstica parda e louca, depara-se com cenas das guerras holandesas e figuras 
históricas nas ruas da cidade, quando as percorre, enfrentando inúmeras dificuldades, em busca de uma pensão por invalidez no INSS. Os delírios do imaginário ancoram-se no cotidiano brasileiro, muito real, e nos recortes de jornais que falam de um Brasil subjugado pelo regime ditatorial e pelo sistema burocrático corrupto. Membro de uma classe oprimida que se bate, durante anos, contra a burocracia do sistema previdenciário que a desnorteia, a descrição da realidade presente da personagem mescla-se às cenas do acontecimento passado, sugerindo que ambos se abatem de forma igualmente cruel sobre a doméstica e sua categoria social. Pode-se, pois, perguntar com o narrador-ensaísta:

Mas respondam-me se trouxe algum proveito a Maria de França e a toda a sua classe a derrocada de Holanda.

Por outro lado, quem ignora a voracidade com que uma parte do planeta explora a outra?

Mais verdadeiro e significativo que Julia M. Enone tenha minado o seu livro com cenas de ocupação e não de expulsão do invasor: elas refletem melhor a nossa realidade e a de todos os países hoje ocupados pelas armas, pelo ouro e por instrumentos menos palpáveis. (p. 138)

O romance expressa simbolicamente as agruras por que passa a heroína, conjugando-as às da população brasileira atual e do passado. Cite-se ainda, como exemplo, o caso dos retirantes que aportam famintos ao Recife e o dos brancos, índios, mestiços, escravos africanos e, depois, também os comandados de Henrique Dias, negros livres, que se agrupam no Arraial do Bom Jesus com Albuquerque. Os compêndios de história destacam o heroísmo desta população que formou um núcleo de resistência aos holandeses durante cinco anos. ${ }^{4}$ Sem que haja nenhuma descrição do Arraial do Bom Jesus e de sua resistência aos holandeses, o reduto é criado no romance como uma impossível cidadela rodeada de serpentes, que causam fome e devastação a seus habitantes e medo à heroína. Comentando a estratégia de Albuquerque que, para se proteger dos invasores, punha sentinelas

${ }^{4}$ Cf. MELLO NETO, 1954. 
nas elevações de Recife, o narrador se pergunta "quem vê as forças que hoje nos invadem?"5

Os dois episódios citados explicitam como, no romance, serão tecidas ligações entre o passado e o presente. Pela leitura justaposta de duas situações de diferentes épocas, quer-se iluminar fatos passados que restam perdidos na memória do país e, ao mesmo tempo, reconhecer-lhes novos significados, na tentativa de aproveitá-los no caso presente.

O romance $A$ rainha dos cárceres da Grécia traz o passado para o presente da história narrada, fazendo com que as personagens de um e de outro tempo se encontrem nas ruas do Recife, desmanchando a distância que os separa no espaço da ficção. O contraponto entre passado e presente acontece pelo discurso do narrador que pontua, com opiniões do presente, a sua visão da presença holandesa no Brasil, presença esta que, mesmo já não sendo notada pelos moradores do nordeste, faz-se sentir na contribuição que trouxe a formação de seu povo.

O romance se constrói, apresentando, ao mesmo tempo, a ficção - o texto -, e a multiplicidade de referências que a elucidam - o metatexto -, ou seja, o escritor deixa ver os andaimes da construção de sua obra. Por isso podem-se detectar, no livro, recursos de que se serve o romancista para revelar/interpretar a invasão do país pela armada holandesa: uma técnica discursiva que cruza planos e funções narrativas. A linguagem dos jornais, da música, do rádio mescla-se à de textos literários e históricos. Eventos históricos combinam-se aos do folclore, como o da Nau Catarineta e do Cavalo Marinho. As errâncias da louca Maria de França, por sua vez, decalcam a geografia do Recife que se torna personagem do romance. Os pontos de referência históricos e geográficos, como a Avenida Martins de Barros, a Rua Riachuelo, a Rua dos Judeus e a Ponte Boa Vista, no entanto, misturam-se, submergidos pelos fluxos das águas invasoras da cidade, e chegam a atingir São Paulo, onde mora

${ }^{6}$ LINS, 1976. p. 139. 
o narrador. Este não nega o Recife real, mas encanta-o, tornando-o uma cidade fantástica, exclusiva do livro. O leitor pode, então, observar o cruzamento da História com a Poesia na tentativa de superação dos limites que as cercam.

Osman Lins situa-se numa vertente da Literatura Brasileira que, embora reabsorva o desvendamento da realidade social na ficção, desenvolve sua obra como marca de diferença na tradição do romance nacional, assumida e levada adiante pelo modernismo dos anos 30. Mescla, em sua produção, o quadro da cultura do país com as conquistas narracionais do romance universal. Por essa característica, A rainha dos cárceres da Grécia alia-se a esse veio contemporâneo da ficção nacional, quando apresenta o reconhecimento de situações do contexto social entremeado com sutilezas metaficcionais, a invasão holandesa no Recife atingindo São Paulo e a todo o povo brasileiro, a circulação das esferas do erudito e do popular.

Se nos remontarmos à opinião de Evaldo Cabral de Mello anteriormente citada, pode-se perceber que o escritor Osman Lins vai basear-se no imaginário popular para a criação do seu romance. Neste, os casos imaginosos e até sobrenaturais sobre a presença holandesa no Brasil se mesclam com a espoliação do povo pelo regime autoritário e corrupto da Colônia e da ditadura militar da era atual, tratados ambos de maneira a concatenar pobreza, ausência de educação e de democracia, como uma constante na história brasileira. Por meio de uma perspectiva irônica, crítica e reflexiva, o narrador permeia sua voz com as vozes dos que falam de outra realidade, ausente da visão oficial, trazendo para a cena literária a discussão do papel histórico do oprimido e das formas arbitrárias de exercício das várias facetas do poder. O romance, portanto, querse interpretante crítico do contexto, na tentativa de mobilizar o leitor e afirmar-se enquanto objeto estético.

No que diz respeito à presença dos holandeses no Brasil, considero bastante enriquecedor o diálogo entre as fontes históricas e literárias que o romance $A$ rainha dos cárceres da Grécia amplia, ao tematizar episódio tão representativo da formação do país. Tanto no campo histórico quanto no literário, podem-se perceber variadas 
nuances e mesmo interpretações opostas do domínio holandês (cf. Bibliografia). De um modo geral, as primeiras fontes tendem a se posicionar francamente ao lado dos portugueses, minimizando as qualidades dos flamengos e considerando "heróis" os que lutaram a favor da coroa portuguesa. Impressionou-me, no entanto, que mesmo tais relatos tenham sido unânimes em afirmar a grande quantidade de luso-brasileiros que aderiram aos invasores, seja por necessidade ou conveniência, seja por falta de outra opção.

Confirmou-se, pois, a impossibilidade de acatamento de uma verdade única e definitivamente estabelecida na construção da história de um país, assim como o complemento que a literatura pode aportar a ela, enquanto elemento participante e transformador do legado da tradição, como se aventou no início desse trabalho. O saber coletivo que a presente leitura do episódio pretendeu recuperar amparou-se, pois, na análise da obra do autor escolhido como objeto de estudo, seja realçando o modo pelo qual se pode unir o sofrimento do povo do Recife à época da invasão holandesa e do regime colonial com o provocado pelo regime ditatorial de 1964, seja destacando as agruras do povo brasileiro como uma constante histórica. O escritor Osman Lins foi, portanto, considerado como intérprete da contemporaneidade que explicita a dialética, a ambivalência e as contradições da identidade de países colonizados, a partir da ficcionalização da presença holandesa no Brasil.

\section{Referências Bibliográficas}

AVANCINI, Elsa Gonçalves. Doce inferno, açúcar, guerra e escravidão no Brasil holandês. (1580-1654). 9. ed. São Paulo: Atual, 1991 (1. ed., 1987)

BOXER, C. R. Os holandeses no Brasil- 1624-1654. São Paulo: Nacional, 1961. CALADO, Frei Manoel. O valeroso Lucideno. São Paulo: Cultura, 1954. 2v. CÂMARA CASCUDO, Luis da. Geografia do Brasil holandês. São Paulo: José Olympio, 1956.

ISER, Wolfgang. Ofictício e o imaginário. Perspectivas de urna antropologia 
literária. Trad. Johannes Kretschmer. Rio de Janeiro: EDUERJ, 1996. (Ed. alemã 1991).

LINS, Osman. A rainha dos cárceres da Grécia. Romance. São Paulo: Melhoramentos, 1976.

MELlo, Evaldo Cabral de. Rubro veio. O imaginário da restauração pernambucana. Rio de Janeiro: Nova Fronteira, 1986.

MELLO, Evaldo Cabral de. O negócio do Brasil - Portugal, os Países Baixos e o Nordeste, 1644-1669. São Paulo: Topbooks, 1998.

MELLO NETO, José Antônio Gonsalves de. Tempo dos flamengos. 2. ed. Recife: Governo do Estado de Pernambuco, Secretaria de Educação e Cultura, Banco do Nordeste do Brasil S.A., 1979. (1. ed. 1954).

MELLO NETO, José Antônio Gonsalves de. Henrique Dias. Governador dos pretos, crioulos e mulatos do Estado do Brasil. Recife: Universidade do Recife, 1954.

RODRIGUES, José Honório. Historiografia e bibliografia do dominio holandês no Brasil. Rio de Janeiro: Departamento de Imprensa Nacional, 1949.

ROSÁRIO, Adalgisa Maria Vieira do. O Brasil filipino no período holandês. São Paulo: Moderna; Brasília: Instituto Nacional do Livro, 1970.

VARNHAGEM, F. A. Os holandeses no Brasil. São Paulo: Cultura, 1943.

\section{Resumo}

Leitura do romance A rainha dos cárceres do Grécia (1976), de Osman Lins, com o objetivo de acompanhar o tratamento que o livro confere a episódios da época colonial, especialmente o da invasão holandesa, interpenetrando-o ao momento ditatorial da década de 70, e de analisar os procedimentos textuais que promovem a ligação entre a história e a literatura, o presente e o passado.

\section{Abstract}

Literarv works as Osman Lins's A rainha dos cárceres da Grécia (1976) frame an image of the Dutch presence in Brazil. This paper intends to mark out how literature shows the intertextual relations between the colonial period and the dictatorial decade of the seventies; and how literary strategies figure the links between literature and history, present and past. 